\title{
Correction to: Release of overexpressed CypB activates ERK signaling through CD147 binding for hepatoma cell resistance to oxidative stress
}

 \\ Byung Kwan Jin ${ }^{5} \cdot$ Geon-Ho Jahng ${ }^{6}$. Insug Kang ${ }^{1}$. Joohun $\mathrm{Ha}^{1}$ • Wonchae Choe ${ }^{1}$
}

Published online: 6 October 2018

๑) Springer Science+Business Media, LLC, part of Springer Nature 2018

\section{Correction to: Apoptosis (2012) 17:784-796 https://doi.org/10.1007/s10495-012-0730-5}

The original version of this article contained a mistake. The bands for HA Tag and t-ERK in Figs. 2d, 2h, 3d are incorrect. The author informs that these errors had no influence in the scientific content of the paper. The corrected figures (Figs. 2 and 3) are given below.

The original article can be found online at https://doi.org/10.1007/ s10495-012-0730-5.

Wonchae Choe

wchoe@khu.ac.kr

1 Department of Biochemistry and Molecular Biology, Medical Science and Engineering Research Center for Bioreaction to Reactive Oxygen Species, Biomedical Science Institute, School of Medicine, Kyung Hee University, \#1 Hoegi-dong, Dongdaemoon-gu, Seoul 130-701, South Korea

2 Department of Obstetrics and Gynecology, School of Medicine, Kyung Hee University, Seoul 130-701, South Korea

3 National Academy of Agricultural Science, Suwon 441-707, South Korea

4 Department of Genetic Engineering, Kyung Hee University, Suwon 446-701, South Korea

5 Department of Biochemistry and Molecular Biology, Neurodegeneration Control Research Center, School of Medicine, Kyung Hee University, Seoul 134-727, South Korea

6 Department of Radiology, Kyung Hee University Hospital-Gangdong, School of Medicine, Kyung Hee University, Seoul 134-727, South Korea 
Fig. 2 Overexpression of CypB protects cells against $\mathrm{H}_{2} \mathrm{O}_{2}$-mediated apoptosis. Huh-7 cells were mock-transfected or transfected with a CypB/WT expression construct and treated with $0,0.6,0.8$ or $1 \mathrm{mM} \mathrm{H}_{2} \mathrm{O}_{2}$ for $24 \mathrm{~h}$. After incubation, cell viability was measured by a, left MTT assay and $\mathbf{a}$, right $\mathrm{LDH}$ release assay. Apoptotic cells were detected by $\mathbf{b}$ PI staining and $\mathbf{c}$ annexin V/PI double staining. d Apoptotic markers were analyzed by immunoblotting. Transfected cells were incubated with 0.8 $\mathrm{mM} \mathrm{H}_{2} \mathrm{O}_{2}$ for $24 \mathrm{~h}$. Whole lysates were separated on $12 \%$ SDS-PAGE gels and immunoblotted with anti-PARP, anti-pro-caspase-3, anti-cleaved caspase-3, anti-Bax, anti$\mathrm{Bcl}-\mathrm{xL}$, and anti-HA probe. $\alpha$-Actinin was used as a loading control. Huh-7 cells were mock-transfected or transfected with a CypB/R95A expression construct and treated with 0 , $0.6,0.8$ or $1 \mathrm{mM} \mathrm{H}_{2} \mathrm{O}_{2}$ for $24 \mathrm{~h}$. After incubation, cell viability was measured by e MTT assay. Transfected cells were treated with $0.8 \mathrm{mM} \mathrm{H}_{2} \mathrm{O}_{2}$. After $24 \mathrm{~h}$ of incubation, cells were harvested, and apoptotic cells were detected with $\mathbf{f}$ PI staining and g annexin V/PI double staining. $\mathbf{h}$ Apoptotic markers were analyzed by immunoblotting. Whole lysates were separated on 10-12\% SDS-PAGE gels and immunoblotted with antiPARP, anti-cleaved caspase 3, anti-Bax, anti-Bcl-xL, and anti-HA probe. $\alpha$-Actinin was used as a loading control. Data are expressed as mean \pm SD of three independent experiments. $* * P<0.05$ versus mock-transfected cells treated with $\mathrm{H}_{2} \mathrm{O}_{2}$; ${ }^{\#} P<0.01$ versus mock-transfected cells treated with $\mathrm{H}_{2} \mathrm{O}_{2}$
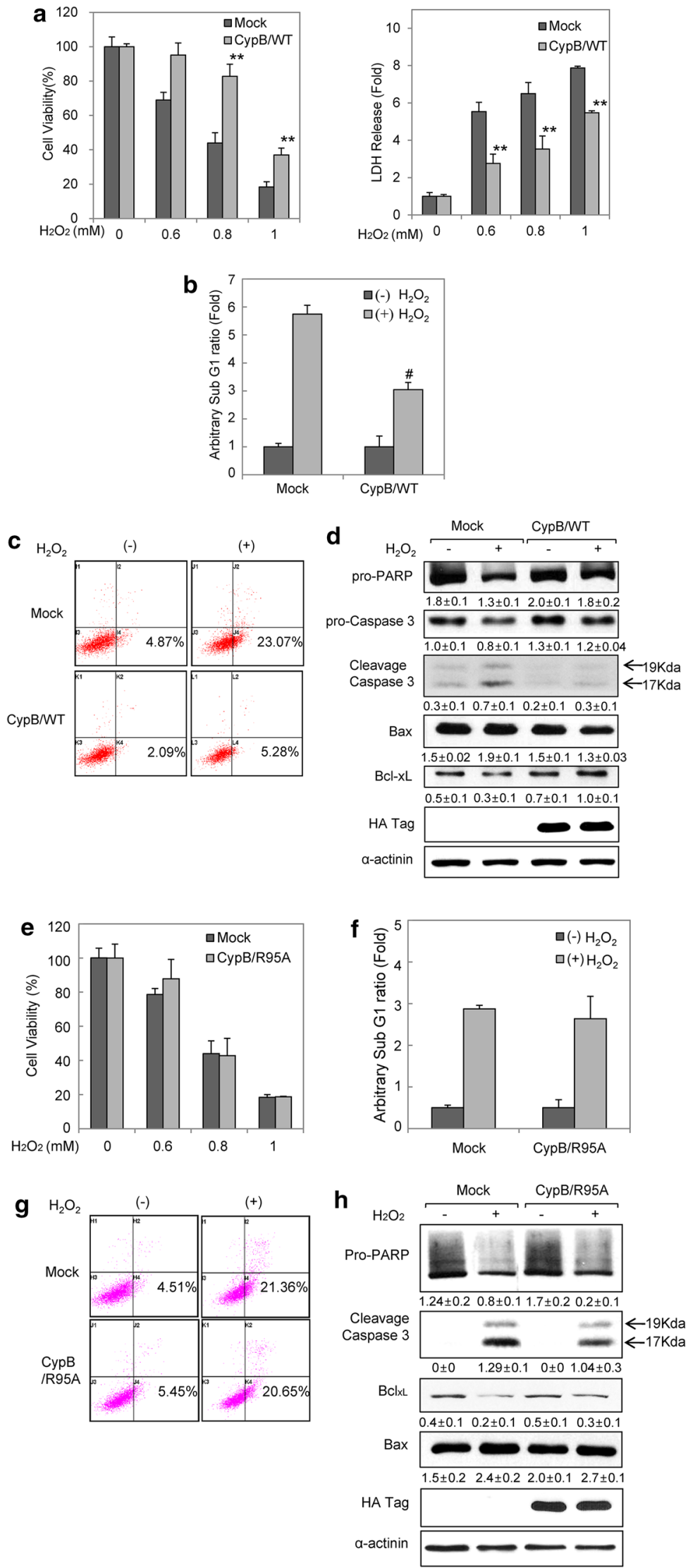

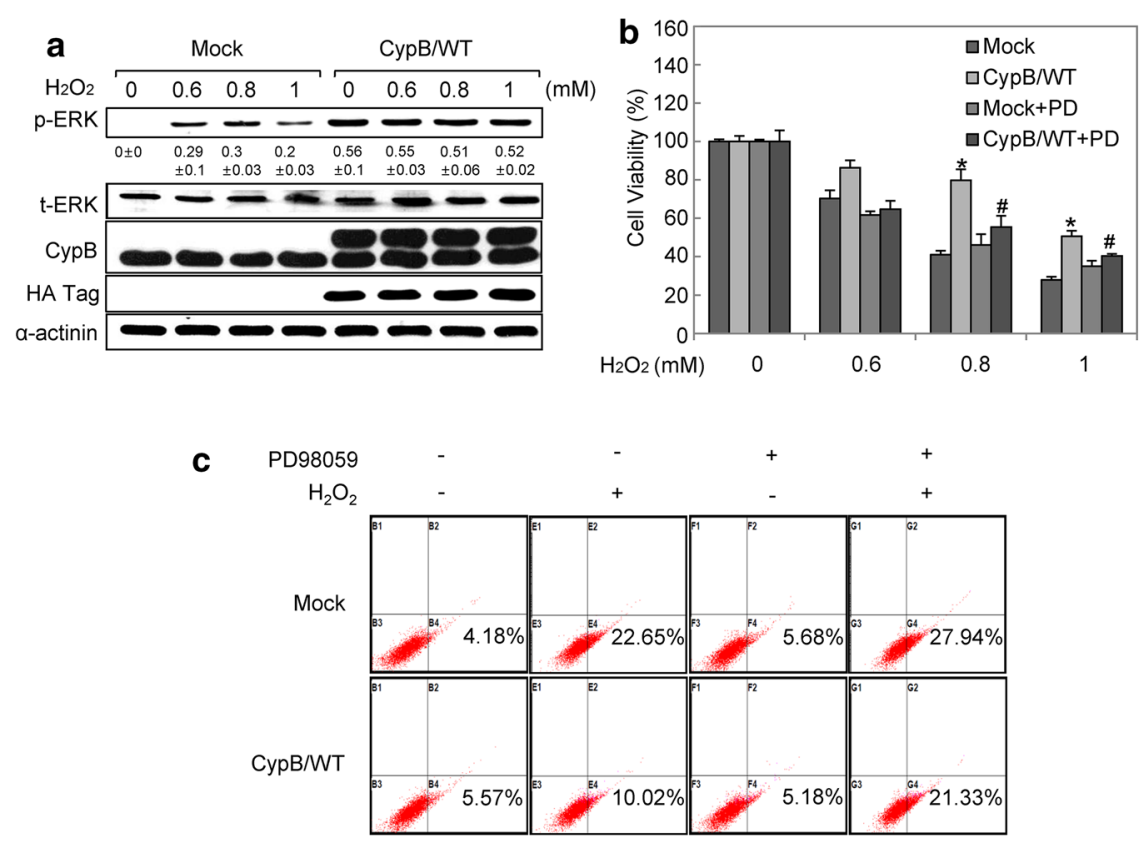

d

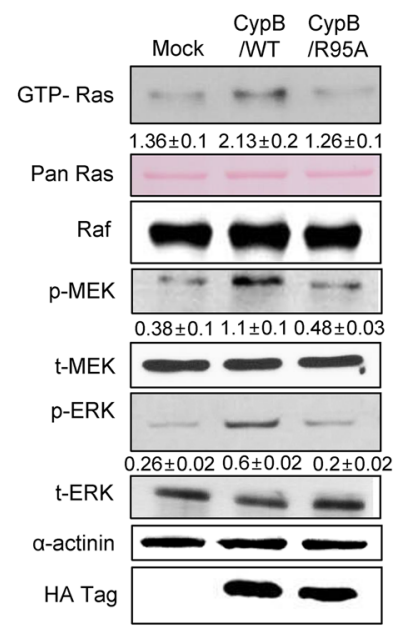

Fig. 3 Overexpression of CypB protects Huh-7 cells though ERK activation. a Transfected cells were treated with $0,0.6,0.8$ or $1 \mathrm{mM} \mathrm{H}_{2} \mathrm{O}_{2}$ for $24 \mathrm{~h}$. Protein levels were detected by immunoblotting with anti-phospho ERK, anti-total ERK, abCAM, or anti-HA probe. $\alpha$-Actinin was used as a loading control. b Transfected Huh-7 cells were pre-treated with the ERK inhibitor PD98059 $(50 \mu \mathrm{M})$. After a 1-h incubation, cells were treated with $0-1 \mathrm{~mL} \mathrm{H}_{2} \mathrm{O}_{2}$ for 24 h. Cell viability was measured by MTT assay. Data are expressed as mean $\pm \mathrm{SD}$ of three independent experiments. ${ }^{*} P<0.05$ versus mock-transfected cells treated with $\mathrm{H}_{2} \mathrm{O}_{2}$; ${ }^{\#} P<0.05$ versus mocktransfected cells treated with $\mathrm{H}_{2} \mathrm{O}_{2}$ after $\mathrm{PD} 98059$ pretreatment. c Apoptotic cells were detected with annexin V/PI double staining. Transfected cells were treated with $0.8 \mathrm{mM} \mathrm{H}_{2} \mathrm{O}_{2}$ after a 1-h pretreatment with PD98059. After $24 \mathrm{~h}$, cells were harvested and analyzed by flow cytometry. d ERK upstream activation was determined by Ras affinity assay and immunoblotting. Transfected Huh-7 cell lysates were analyzed by Ras affinity assay and separated on $12 \%$ SDS-
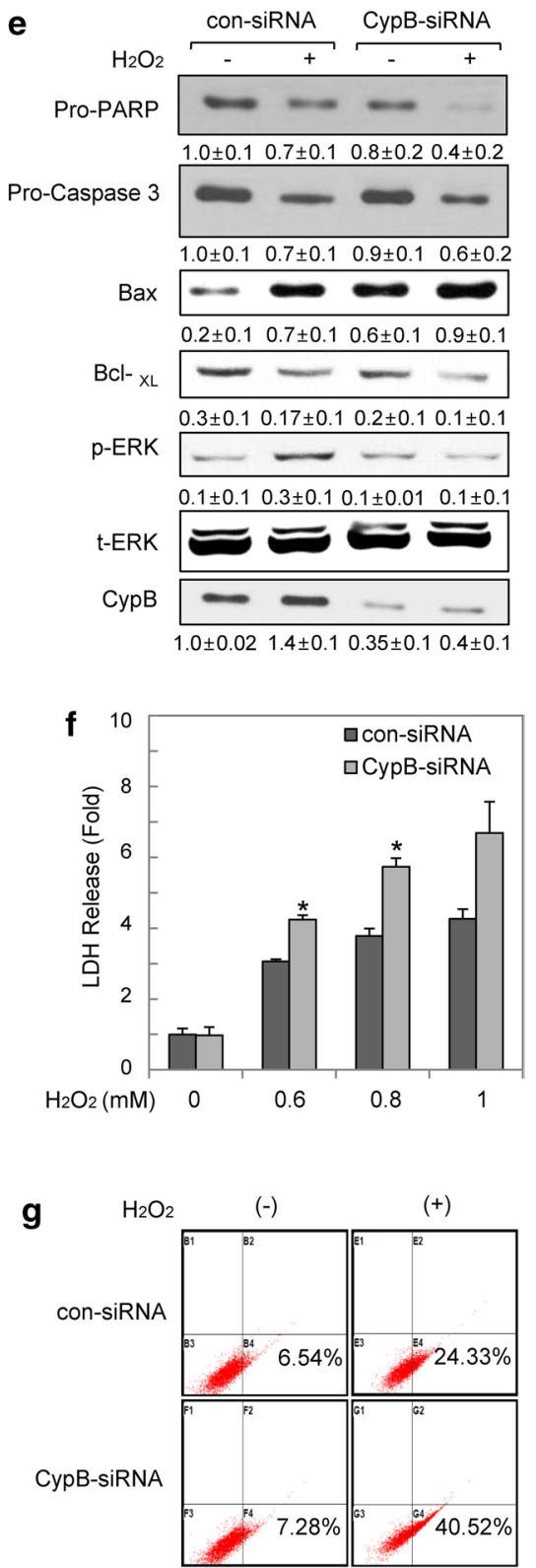

PAGE gels. Equal protein loading was ensured by Ponceau S staining and pan-Ras immunoblotting of the input. Immunoblotting was performed with antibodies against Raf, phospho-MEK, total-MEK, phospho-ERK, total-ERK, and the HA tag. $\alpha$-Actinin was used as a loading control. e Huh-7 cells were transfected with con-siRNA or CypB-siRNA and treated with $0.8 \mathrm{mM} \mathrm{H}_{2} \mathrm{O}_{2}$ for $24 \mathrm{~h}$. After incubation, apoptotic markers were analyzed by immunoblotting. Whole lysates were separated on 10-12\% SDS-PAGE gels and immunoblotted with anti-PARP, anti-pro-caspase-3, anti-Bax, anti-Bcl-xL, anti-phospho ERK and anti-total ERK. f Transfected cells were treated with $0,0.6,0.8$ or $1 \mathrm{mM} \mathrm{H}_{2} \mathrm{O}_{2}$ for $24 \mathrm{~h}$. After incubation, cell viability was measured by LDH-release assay. Data are expressed as mean $\pm \mathrm{SD}$ of three independent experiments. ${ }^{*} P<0.01$ versus con-siRNA transfectants treated with $\mathrm{H}_{2} \mathrm{O}_{2}$. g Apoptotic cells were detected with annexin V/PI double staining. After siRNA transfection, cells were incubated with 0 or $0.8 \mathrm{mM} \mathrm{H}_{2} \mathrm{O}_{2}$. After $24 \mathrm{~h}$, cells were harvested and analyzed by flow cytometry 